\title{
LA RELIGIÓN COMO RELACIÓN PRÁCTICA DE RECONOCIMIENTO EN LA FENOMENOLOGÍA DEL ESPÍRITU DE HEGEL
}

\section{Religion as a Practical Relation of Recognition in Hegel's Phenomenology of the Spirit}

\author{
Miguel Ángel Nación Pantigoso \\ Universidad Femenina Sagrado Corazón \\ Lima - Perú \\ https://orcid.org/0000-0001-7524-1640 \\ miguelnacionp@unife.edu.pe
}

\begin{abstract}
RESUMEN
El presente artículo busca entender el papel que juega la religión en Hegel, en particular, en su obra Fenomenología del Espíritu tomando al concepto de reconocimiento como clave hermenéutica de la obra hegeliana. Para esto, primero ubicamos históricamente la aparición y recepción del concepto de reconocimiento en el Idealismo Alemán. Luego, presentamos la estructura de relaciones de reconciliación entre sujeto y objeto que supone la Fenomenología. Finalizamos, destacando el papel que tiene la religión como categoría de la autoconciencia de la estructura de relaciones de reconocimiento de la sociedad moderna.
\end{abstract}

\section{Palabras clave:}

Reconocimiento, Fenomenología, Espíritu, Religión

\begin{abstract}
This article seeks to understand the role that religion plays in Hegel, specially, in his work Phenomenology of the Spirit, taking the concept of recognition as the hermeneutical key of the Hegelian work. For this, we first historically locate the appearance and reception of the concept of recognition in German Idealism. Then, we present the structure of reconciliation relationships between subject and object that Phenomenology supposes. We conclude by highlighting the rolethat religion has as a category of self-awareness in the structure of recognition relationships in modern society.
\end{abstract}

\section{Keywords:}

Recognition, Phenomenology, Spirit, Religio 


\section{INTRODUCCIÓN}

En los estudios contemporáneos sobre Hegel existe la tendencia a tomar el concepto de reconocimiento como la clave hermenéutica de su obra. Así vemos que para Axel Honneth (Honneth, 1992), el reconocimiento ayuda a entender las reflexiones éticas del joven Hegel de la época de Jena. Otros autores como Robert Williams (Williams, 1997) han ido más lejos y afirman que podemos hacer del reconocimiento la clave hermenéutica de la obra completa de Hegel, es decir, que la obra hegeliana sería una reflexión sobre el reconocimiento y sus consecuencias prácticas, en la cual libertad, reconocimiento y ética están inextricablemente entretejidas, ya que la libertad presupone y requiere del reconocimiento; ý éste es el proceso en el cual y por el cual la libertad se actualiza en la vida práctica intersubjetiva. Por esto, el reconocimiento es central en la comprensión de la filosofía del Espíritu de Hegel. Este es en términos generales el consenso, claro con sus matices, entre los investigadores que van desde Honneth hasta Williams pasando por autores como Terry Pinkard (Pinkard, 1994) y Robert Pippin (Pippin, 2008).

Lo interesante de esto es que invita a reflexionar sobre los alcances que puede tener el concepto de reconocimiento para echar nuevas luces a obras clásicas del corpus hegeliano, sobre todo respecto de tomar a la filosofía de Hegel como fuente de crítica al egoísmo y al individualismo en su descentramiento del sujeto mediado por el otro, pero que, al mismo tiempo, defiende la realización de la autonomía dentro de la comunidad. En este sentido, el caso de la Fenomenología del Espíritu es más que seductor, porque lleva a plantear una serie de cuestionamientos a los supuestos metafísicos de la subjetividad cosificadora y al sentido de la obra dado por Hegel. Honneth en su momento afirmó que en la Fenomenología el reconocimiento perdía su sentido práctico e intersubjetivo para asumir el sentido teórico del Espíritu, totalidad que se objetiva a sí misma para alcanzar el Saber Absoluto. Sin embargo, el propio Honneth ha trabajado las implicancias prácticas del reconocimiento en la sección de la Autoconciencia (Honneth, 2008), por no comentar la reactualización que hizo de la Filosofía del Derecho a partir de este concepto (Honneth, 2001). Basta con recordar aquí como en la sección de la Autoconciencia de la Fenomenología, el reconocimiento surge como categoría en el momento en el que el sujeto autoconsciente se encuentra con otra autoconsciencia, viéndose en la necesidad de desplazar el sentido meramente teórico de las categorías de la conciencia para tomar un sentido que implique la capacidad del otro de autolimitar su deseo.

A partir de la sección de la Autoconciencia, el autoconocimiento de sí que va logrando el sujeto va en ascenso hasta el grado de ser consciente que él es parte de una estructura de relaciones que media su ser autónomo. Para esto el desarrollo de las relaciones entre el sujeto y el otro se desenvuelven en la tensión frente a la objetividad del otro y los momentos de reconocimiento en este, lo que no significa identidad, sino unidad, vinculación con una realidad superior de la cual uno es parte y sin la cual no tiene sentido, porque en su vínculo con el otro, el sujeto conoce quien es.

El argumento de Hegel en la Fenomenología expone esta estructura de relaciones en términos formales hasta la sección de Razón. En adelante, es decir, a partir de la sección Espíritu, el argumento muestra cómo se da la estructura de 
relaciones de reconocimiento en la historia. Sin embargo, es en la sección Religión que la unidad a la realidad superior se vuelve consciente para el sujeto. En particular, el cristianismo va a cumplir la función de unir al sujeto a una comunidad en la que el sujeto se reconoce como un individuo a través del vínculo entre su voluntad particular con la voluntad universal de Dios. Este papel del cristianismo fue crucial porque dio el sustento dentro del idealismo alemán para la crítica del orden feudal y la defensa de una sociedad liberal.

\section{Reconocimiento en el marco del idealismo alemán}

Dentro de la historia de la filosofía alemana, el concepto de reconocimiento surge al finalizar la Guerra de los Siete Años (1763) que transformó a Prusia en el mayor poder de Europa. Para esta época Alemania tal como la conocemos hoy en día no existía, sino tan solo había un conjunto deterritorios germano parlantes vinculados a un agonizante Sacro Imperio Romano Germánico, que era principalmente una unidad política sui generis sin unidad cultural, dividida entre protestantes y católicos, pero que en cierta medida compartían una lengua con variaciones geográficas. Las diferentes divisiones solo podían alcanzar unidad en el discurso de sus intelectuales, y la filosofía no fue la excepción (Pinkard, 2002).

Entre los intelectuales alemanes la tarea consistía en enfrentar la irrelevancia política y cultural de la burguesía sometida al viejo orden corporativo de la época feudal. La idea de reconocimiento expresó la forma filosófica de desarrollar esta tarea a través de la exhortación a la emancipación del orden aristocrático y la defensa del primado de la igual dignidad moral de todos los ciudadanos. Será Immanuel Kant quien inicie esta revolución del pensamiento con sunoción de respeto universal. (Honneth, 2018)

Para Kant la razón moral coincide con lo que todos los seres racionales pueden considerar moralmente correcto. En el contexto de la acción, la razón práctica interviene dando reglas o "máximas" que debemos cumplir si queremos comportarnos de una manera moralmente correcta con nuestros semejantes. Estas leyes morales de la razón están interiormente motivadas, pero no por el deseo subjetivo y contingente, sino por el sentimiento de respeto que inspira otro ser de igual dignidad que el sujeto. Sin embargo, no está claro cómo el sujeto puede encontrar ese motivo en sí mismo (Kant, 1989).

Kant sostiene que los motivos morales establecen una relación de causalidad. En este sentido, la acción moral es el resultado de la inclinación a respetar a los otros porque no podemos evitar ver en estos la imagen fiel de los esfuerzos que la ley racional como tal nos requiere (Honneth, 2018). Este ver o, mejor dicho, tener experiencia de la ley racional significa ser consciente del a priori de la moralidad humana: el respeto; con el cual rompemos el amor propio disociador. Este sentimiento, a diferencia de los demás que nos son impuestos por nuestra naturaleza empírica y hacia los cuales somos pasivos, es producido por la propia razón práctica en tanto somos sujetos racionales que habitamos un mundo inteligible donde reina la libertad y desde la cual se autodetermina. Así, ser conscientes de ser libres y de habitar un mundo espiritual de seres libres lleva a autodeterminarnos en nuestra acción en consideración a otros seres libres con los cuales convivimos. 
Para Kant que la razón práctica produzca un sentimiento supone estar convencido del valor de un determinado objeto, de tal modo que tiene un efecto definido en nuestra economía emocional: limitar nuestras inclinaciones egoístas. El respeto no significa otra cosa que atribuir un valor de tal grado a un objeto que nos obligue a suspender nuestros intereses egoístas para estar a la altura de este. Sin embargo, qué objeto debe poseer tal valor como para producir esta limitación de las inclinaciones egoístas de nuestra naturaleza. Kant reitera que el único objeto digno de tal respeto es la misma ley moral, el mandamiento de la razón encarnada en los otros sujetos humanos; ya que: "Todo respeto por una persona es, propiamente hablando, sólo respeto por la ley [...], de la que él [esa persona] nos ofrece un ejemplo". (Honneth, 2018, pág. 97)

De acuerdo con Kant, el otro se nos aparece de forma ejemplar como un valor incondicional que posee la ley moral, de modo tal que pone un límite a nuestro interés egoísta. Es decir, como sujetos racionales estamos motivados a someternos a la ley moral porque nuestros semejantes representan para nosotros un objeto sensible, concreto, que nos obliga a pensar en un valor que rompe el amor propio. Si la ley moral, racional y perfectamente abstracta puede acercarse a la intuición y por tanto al sentimiento, es debido a que todo ser humano incorpora sensible y ejemplarmente un valor que exige nuestro respeto y que nos induce a suspender nuestros fines egoístas.

La tesis kantiana sobre la motivación de la acción moral tiene una implicancia central para la idea de reconocimiento. Con su concepto de respeto Kant ha construido un puente entre la sensibilidad y la razón. La ley de la razón práctica es una operación cognitiva, pero no es ni absolutamente a priori ni puramente sensible; sino, más bien, proporciona la percepción de un sujeto empírico, sensible a la racionalidad, hasta el punto de que la intuición sensible y el conocimiento racional coinciden. De este modo, el respeto como intuición intelectual ejerce una acción sobre nuestra dinámica motivacional que consiste en llevarnos a abandonar nuestras inclinaciones egoístas. En otras palabras, para Kant la razón práctica construye un puente entre la naturaleza y el Espíritu a través de la relación de respeto que cada uno de nosotros debe al otro cuando reconoce en este el esfuerzo por realizar la ley moral.

Sin embargo, para Kant la necesidad de aprecio o reconocimiento social no está considerada en su concepto de respeto. Piensa, más bien, siempre desde el punto de vista de un sujeto obligado hacia su prójimo y no desde la perspectiva de un sujeto que aspira al reconocimiento de los demás. Solo en Hegel encontraremos algo así como una necesidad de reconocimiento, la cual debe entenderse como una necesidad espiritual antes que psicológica.

La primera vez que se formula la relación de reconocimiento en Hegel es en 1802, en un artículo sobre la ley natural y, luego, en el Sistema de la Eticidad donde es desarrollada ampliamente. Al respecto, Honneth resalta el concepto de Sittlichkeit (Eticidad). Éste refiere a la vida ética absoluta, vale decir, un estado ideal de la vida social donde los individuos han realizado sus capacidades individuales teóricas y prácticas, y, además, sus interacciones reciprocas han sido totalmente desarrolladas. Este nivel representa la completa encarnación del Espíritu tal cual es en el mundo (Honneth, 1995). Después de estos textos, el 
concepto de Sittlichkeit será desarrollado, también, en la Primera filosofía del Espíritu $(1803 / 4)$. Posteriormente, pareciera que el desarrollo de este concepto de reconocimiento se truncó, ya que la Fenomenología del Espíritu (1807) iría por los rumbos del Saber Absoluto y del desenvolvimiento de la conciencia.

Hegel formula su noción de reconocimiento en términos de una relación de lucha, para esto se apoya en Hobbes, Aristóteles y Fichte, representantes de las tesis fuertes de la filosofía social del momento. De Hobbes toma la tesis de la lucha entre individuos como factor constituyente de la vida social. A través de la lucha entre unilateralidades, Hegel dinamiza los vínculos sociales y socializa los criterios normativos de integración. Así mismo, toma de Aristóteles la tesis de la anterioridad de la comunidad respecto al individuo, por lo que rechaza el atomismo individualista. Sobre estas bases, sostiene la primacía de la intersubjetividad que se transforma a través del conflicto de sus partes. Para Hegel la intersubjetividad es la condición de posibilidad de toda forma de interacción entre los agentes sociales y de toda forma de comportamiento individual. En este sentido, la individuación es una forma que toman los vínculos intersubjetivos y no la desaparición de estos.

Con respecto a Fichte, Hegel toma el concepto de reconocimiento aparecido en su Fundamento del Derecho Natural (1796). Ahí Fichte sostiene que la autoconciencia, el fundamento teóricopráctico trascendental, es incapaz de fundarse a sí misma, por lo que requiere de la determinación recíproca y circular de otra autoconciencia igual de libre como ella. En la relación de reconocimiento la conciencia satisface esta necesidad, ya que logra conocerse a sí misma como radicalmente libre al momento de ser reconocida en su propia libertad por otra conciencia, la cual, a su turno, también debe ser reconocida como libre. De este modo, la autonomía de la conciencia exige la relación recíproca del reconocimiento de cara a fundamentarse. La consecuencia del mutuo reconocimiento es el espacio objetivo y común de la ley, en donde las conciencias libres recíprocamente limitan su propio campo de acción en vista de la acción de los otros. Aquí resalta el carácter negativo de la noción fichteana de reconocimiento al centrarse en la autolimitación simultánea de las conciencias por el riesgo de invadir la esfera de acción del otro, que da pie al surgimiento de la libertad personal.

Hegel cambia el sentido negativo del reconocimiento fichteano. Asume el esquema circular del mutuo reconocimiento como condición de la autoconciencia, pero le aplica una lógica directa y afirmativa por la cual las conciencias se afirman recíprocamente, convirtiéndose en verdaderas autoconciencias autónomas. En este sentido, la libertad individual no se define por la auto-limitación de la propia acción, sino más bien, por la afirmación de sus capacidades como agentes en diferentes niveles de relaciones prácticas: emocional, legal e institucional. En estas dimensiones, las autoconciencias afirman sus cualidades prácticas en forma intersubjetiva y formativa hasta alcanzar la condición de sujetos autónomos. Este es un proceso de socialización que lleva a la individuación.

El aprendizaje social para llegar a ser individuo se pone en funcionamiento a través del conflicto. La relación de reconocimiento es una lucha por afirmar las propias capacidades que permitirán a 
cada uno ser autónomo. En las versiones contractualistas la lucha es un concepto que ayuda entender la naturaleza de la relación entre los individuos antes del contrato fundacional de la comunidad política. Sin embargo, la lucha por el reconocimiento se distingue de estas versiones porque no es anterior a la comunidad, sino el modo por el cual la individualidad se afirma frente a ésta (Siep, 2011 ). Para que esto se ponga en marcha, primero, debe sufrirse un perjuicio moral que es sentido como carencia de reconocimiento. Luego, viene la reacción violenta de quien se siente no reconocido con el fin de redefinir los criterios evaluativos y se valore lo que hasta ese momento no era reconocido. En este sentido, Hegel interpreta el crimen. Señala que el ataque no está dirigido centralmente a la propiedad, sino, a la persona misma, en tanto, valoración encarnada. El conflicto termina solo cuando se establecen nuevos criterios evaluativos que descubren nuevas dimensiones de la identidad práctica de los sujetos. Honneth hace notar que el conflicto permite tomar conciencia de los variados aspectos de la propia individualidad al ser reconocidas públicamente, y, asimismo, ser conscientes que la formación de la autonomía va de la mano con el descubrimiento de la interdependencia mutua con el otro (Honneth, 1992).

Pero, queda una interrogante ¿cómo se socializa la autonomía? Entre los años 1816 y 1817 Hegel ofrece una serie de conferencias sobre filosofía política donde aborda su noción de libertad que posteriormente quedará expuesta en su Filosofía del Derecho. Ahí desarrolla las líneas fundamentales de su teoría respecto del sentido de la realización institucional del concepto de libertad. Para Hegel, si el sujeto se relacione a través de sus actos voluntarios con un objeto en el mundo que se mantiene ajeno, porque no puede reconocerlo como una extensión de sí mismo, entonces, no es aun verdaderamente libre. Por esto, el sujeto solo puede encontrar la verdadera libertad siendo consigo mismo en este otro en forma tal que pueda experimentar las características o particularidades del otro como algo en lo que pueda identificarse. Ser consigo mismo en el otro significa que el sujeto libre dirige sus esfuerzos a encontrarse a sí mismo en un mundo cuya estructura es una expresión de su propia voluntad. Para Honneth, Hegel es consciente que la única manera de hacer posible esto es desarrollar las condiciones institucionales, legales y sociales que permitan a los sujetos restringir recíprocamente sus voluntades como expresión de sí mismos, es decir, a través del respeto mutuo. Solo así, los fines subjetivos podrán encontrar en la objetividad un espacio de realización sin que pierda su carácter objetivo, permaneciendo consigo mismo en el otro. Ahí estamos ante el núcleo central de la estructura de las relaciones de reconocimiento.

\section{La estructura de relaciones en la Fenomenología del Espíritu:}

En 1805 Hegel había planificado publicar su sistema filosófico. En febrero de 1806 ya tenía la primera parte lista para la imprenta, a la cual había titulado Ciencia de la Experiencia de la Conciencia, pero, posteriormente le cambio el título por Fenomenología del Espíritu, libro que fue publicado en 1807. En su introducción se aborda el sentido del concepto de fenomenología, que para él tiene dos aspectos inseparables: la experiencia de la conciencia y la historia. Ambas se entrelazan y se presentan como el camino de la experiencia de la conciencia 
que va desde las formas más inmediatas de la conciencia natural hasta el Saber Absoluto. En este camino van apareciendo las categorías, las formas de ser y de aparecer del Espíritu.

El camino emprendido en la Fenomenología se caracteriza por remplazar las creencias erradas por otras verdaderas. Este cambio de creencias significa una expansión del horizonte de comprensión a través de la superación de las contradicciones encontradas en una realidad "aparente". El significado de aparente consiste en que lo percibido y conocido, lo es respecto de una categoría de la conciencia y no desde el punto de vista del Saber Absoluta. Por esto, toda apariencia nos lleva a un conocimiento parcial, un error, no a la verdad. La verdad es la totalidad que solo puede ser comprendida desde el Saber Absoluto. Sin embargo, el carácter "aparente" no implica dejar de lado este conocimiento parcial, sino, más bien, debemos "verlo" desde el punto de vista del proceso de autoconocimiento del Espíritu, esto quiere decir, verlo como un paso más hacia la verdad, la cual aún no ha sido desplegada en toda su realidad. Es aquí en donde toma sentido la contradicción hegeliana: la diferencia u oposición entre una realidad mayor que supera la comprensión de la categoría a partir de la cual se percibe la realidad aparente, y, por eso, debe superarse en otra de mayor comprensión.

Desde el inicio del camino con la conciencia natural, Hegel anticipa la perspectiva del Saber Absoluto. Conciencia natural y Saber Absoluto o punto de vista de la ciencia son parte de un solo camino. En el inicio, la conciencia natural conoce a los objetos y a sí misma en oposición a estos; mientras que desde la mirada de la ciencia se reconoce la identidad del yo y el objeto: autorreconocimiento puro en la alteridad absoluta. Sin embargo, esta perspectiva debe justificarse ante la conciencia natural, ofreciéndole el ascenso a la perspectiva de la ciencia a través del examen y refutación inmanentes de todas las formas de conocimiento, de todos los modos de acción y de todas las configuraciones de la cultura que están marcadas por la convicción de oponer al objeto y al yo (Siep, 2000).

Para entender el ascenso al Saber Absoluto debemos recurrir a las nociones hegelianas de absoluto y de sistema. Como sabemos, Hegel tiene una concepción holística de la filosofía, en donde la verdad alcanza un significado tanto epistémico como ontológico. De este modo la unidad del todo, vale decir, el sistema de categorías, no solo nos expresan la verdad sino la realidad de la unidad entre la realidad sustancial y el sujeto autorreflexivo. Sistema y Absoluto están entrelazados y se expresan como Espíritu. Así pues, se debe hacer el esfuerzo de comprender y justificar cualquier concepto o proposición en la interconexión con el resto de conceptos y dentro de su propio dominio. A la vez, entender que los conceptos están interconectados por el desarrollo orgánico de estructuras teóricas que van de las más simples a las más complejas pero que se explican recíprocamente entre sí.

Para que la conciencia natural alcance el punto de vista de la ciencia se requiere de un proceso: la historia cultural o historia humana. En el camino de la experiencia de la conciencia entramos también en un proceso espiritual en el que los conceptos se presentan sucesivamente y se reflejan en varios elementos diferentes: política, cultura, religión, etc. Cada una de estos hace una contribución necesaria al todo y a su 
resultado, vale decir, el punto de vista del Espíritu, con lo que éste se muestra como una necesidad y finalidad inmanentes. Tal como lo plantea Hegel cada aporte del proceso espiritual implica ampliar la comprensión que tiene la conciencia de sí misma dentro de un proceso que tiene ese fin y en donde emergen los modos de la autoconciencia. Por eso, la perspectiva de la ciencia, el Saber Absoluto, es esencialmente un resultado, que solo al final es lo que realmente es. Así pues, Hegel parece mostrarnos que la historia mundial es un proceso de mano invisible con un resultado consciente.

Jon Stewart reconstruye el camino sistemático de la Fenomenología del Espíritu al exponer su unidad formal, es decir, el movimiento unitario de los contenidos de las secciones y de los capítulos individuales. Para esto establece la unidad del texto sobre la versión revisada del índice que Hegel escribió después de la finalización del trabajo y, luego, prueba este esquema organizativo contra varios pasajes a lo largo del libro que sirven como indicadores de la estructura sistemática en su conjunto. Hecho esto se puede observar una imagen de la economía general del texto que contiene capítulos y secciones paralelos, como lo indicó Hegel en su carta a Schelling. Con esto se podría situar los análisis individuales en su contexto adecuado (Stewart, 2010).

En el primer esbozo de la Fenomenología, Hegel usó los numerales romanos para las secciones "Certeza Sensible", "Percepción", "Fuerza y Entendimiento", "La verdad de la certeza de sí mismo", "Certeza y verdad de la razón", "El Espíritu", "La Religión" y finalmente "El Saber Absoluto". Esta organización causó una gran confusión con respecto a la extensión desproporcionada de algunas secciones frente a otras. Por ejemplo, la diferencia de páginas entre las secciones de "Certeza Sensible" y "Espíritu". Por esto, Hegel revisó este índice de una manera esclarecedora cuando estaba leyendo las pruebas del libro y realizó un segundo esquema utilizando las letras latinas A, B y C para los capítulos "Conciencia", "Autoconciencia" y "Razón" respectivamente. De ahí la tesis que la Fenomenología constaba originalmente de solo tres capítulos. En ese momento también colocó las letras dobles AA, BB, CC y DD para las secciones de "Razón", "Espíritu", "Religión" y "Saber Absoluto", respectivamente (Stewart, 2010).

Pero ¿qué hace que este simple cambio sea esclarecedor? De acuerdo con Stewart, lo que Hegel quiere es indicar con las letras individuales del segundo índice un conjunto de estructuras paralelas. Por lo tanto, "Conciencia" y "Autoconciencia" están destinadas a seguir su curso de una manera paralela entre sí. Por otro lado, lo que indica con las letras dobles es el sentido de la dialéctica: volver al principio. En este sentido, "Razón", "Espíritu" y "Religión" vuelven al punto de partida de la "Conciencia" y a trabajar sobre el mismo material, pero bajo el ámbito que cada uno gobierna. Esto queda claro en la sección "Razón", en donde se encuentra la clave para entender la estructura de la obra.

Para Stewart la sección "Razón" tiene que entenderse en relación al comienzo de la dialéctica y trabajando a través del mismo material de las secciones "Conciencia" y "Autoconciencia", pero en un nivel superior. Lo que significa que "Razón" implica "Conciencia" y "Autoconciencia" tomadas juntas y no como unidades individuales. De acuerdo con Stewart, las letras simples y las letras dobles que preceden a la "Conciencia", Autoconciencia y "Razón", respectivamente, están destinadas a 
indicar los paralelismos entre las diversas secciones del texto. La "Conciencia" y la "Autoconciencia forman unidades independientes que se construyen una sobre la otra. Por eso, le corresponde a la primera la A y a la segunda la B. Luego viene la "Razón" que también forma una unidad independiente, por eso le corresponde la C. Sin embargo, le precede también las letras dobles AA. Con esto Hegel quiere decir que la dialéctica en este punto vuelve a la posición original en la sección "Conciencia" representada por la A y trabaja a través de las mismas formas de la Conciencia de nuevo, pero en un nivel diferente. Así mismo, las secciones de "Espíritu" y "Religión", que también están representadas con letras dobles BB y CC, respectivamente, regresan también a la sección que su letra indica y vuelve a trabajar con cada una de las figuras de la sección aludida, pero bajo el dominio de la sección en la que se encuentran.

Las tres partes de la sección "Razón" tienen las letras simples A "La razón observadora"; B "La realización de la autoconciencia racional mediante sí misma"; y C "La individualidad que es para sí real en y para sí misma". Por las letras sabemos que las dos primeras secciones parecen corresponder con las formas de la "Conciencia" y la "Autoconciencia", respectivamente. En cambio, la sección final no tiene un paralelo previo, por lo que significa que ahí la dialéctica llega a su final, es decir, a la unidad del sujeto y el objeto. En efecto, en la parte $\mathrm{C}$ de la sección "Razón", la autoconciencia finalmente llega a darse cuenta de lo que desde el punto de vista de la Ciencia se sabe: la unidad de sujeto y objeto. Lo que la autoconciencia aprende de "La virtud y el curso del mundo" es que el mundo no es malo, ni otro externo opuesto al sujeto individual o a la esfera moral: la autoconciencia. "Estando ahora absolutamente seguro de su realidad, ya no busca solo realizarse como un fin en oposición a la realidad a la cual está inmediatamente confrontado" (Hegel, 2009, pág. 494). Por el contrario, para Hegel el mundo está en armonía con el individuo, lo que le permite satisfacer sus necesidades de manera cooperativa con los demás. Ahora, el individuo es capaz de identificarse con la esfera externa y verse a sí mismo en ella por medio de su trabajo y actividad

\section{Religión como forma de la autoconciencia}

El sentido de la sección "Religión" es el de dar cuenta de la conciencia de sí mismo del Espíritu. Esta autoconciencia es lo que Hegel llama Espíritu Universal o Espíritu Absoluto. "El Espíritu concebido como objeto tiene para sí el significado de ser el Espíritu Universal que contiene en sí mismo toda la esencia y toda la actualidad" (Hegel, 2009, pág. 539). Esta autoconciencia está implícita en la conciencia que el Espíritu tiene de su esfera objetiva, pero debe hacerse explícita en el curso de la dialéctica. Por eso, la Religión representa la explicitación de los presupuestos de esta autoconciencia. Esto es especialmente importante en el caso de la "Religión revelada", porque en ella el Espíritu es consciente de sí gracias a la revelación de Dios en la tierra, y, específicamente, con Cristo es autoconsciente que Dios y lo Absoluto no son de otro mundo o algo diferente del hombre, sino que Dios es hombre o Espíritu en el mundo.

Queda claro que para entender la Religión debemos remitirnos al Espíritu. Pero ¿qué es el Espíritu? Con el concepto de Espíritu, Hegel refiere a las relaciones éticas inmediatas de una comunidad particular. Esto significa que hasta la 
sección "Razón" se abordó las relaciones comunitarias en un sentido formal, abstraídas del contenido espiritual del contexto histórico y social concreto. Por eso, la sección "Espíritu" incluye la descripción histórica de comunidades concretas y el ingreso del papel formativo de la historia en el camino hacia la perspectiva de la ciencia. La historia, o, como la llama Hegel, historia actual, juega el papel de llevar las formas de la mera conciencia a formas de mundo y mostrar, así, como las comunidades reales, en el sentido estricto de la palabra, median las afirmaciones verdaderas. Para Hegel toda determinación de la verdad está mediada por la historia de la comunidad que llegó a realizarla.

Las distintas formas de autoconciencia del Espíritu corresponden a las identidades de las comunidades históricas con las cuales estas pueden volver sobre sí mismas a través del arte, la religión y la filosofía para conocer lo que la determina. En las formas de autoconciencia del Espíritu se refleja lo que significa ser una persona o un agente hábil en una forma de vida especifica. En este sentido, las formas del Espíritu permiten la reflexión sobre los fundamentos definitivos de las creencias y las acciones, es decir, los fundamentos de la vida práctica. Esta reflexión considera lo que las personas toman como criterios normativos de la realidad espiritual y la relación que tienen con éstos en la determinación de su identidad práctica. Las concepciones religiosas se encuentran entre estas formas del Espíritu. Por esto Terry Pinkard afirma que la religión es una forma social institucionalizada en la cual la comunidad reflexiona sobre lo que considera es el fundamento de la vida práctica; en términos de Hegel, es la conciencia a partir de la cual se muestra lo que para la comunidad es existente en y para sí misma. (Pinkard, 1994)
Los objetos de reflexión religiosa son los principios absolutos y gobernantes de las formas de vida que se entienden como lo divino y lo sagrado para la comunidad. La reflexión religiosa se caracteriza por tener la forma de la representación (Vorstellung), es decir, lo que hoy definiríamos como formas simbólicas que se muestran en los ritos y las imágenes. Estas formas no solo tienen un sentido cognitivo, sino también, y fundamentalmente, tienen un sentido práctico (Pinkard, 1994), que hace presente a la consciencia a través de imágenes las relaciones conceptuales entre entidades de aquello que determinan esencialmente lo que somos o lo que es absoluto en la vida humana. A partir de estas determinaciones fundamos nuestras afirmaciones de la vida práctica como seres racionales.

La representación del fundamento último o absoluto de la forma de vida en la práctica religiosa lleva a los agentes individuales más allá de su estado de natural egoísmo, es decir, su mero punto de vista, hacia un estado comunitario o de comunidad en el cual estos aceptan razones, obligaciones y proscripciones que les imponen límites objetivos en sus creencias y acciones. Aquí la religión cumple con representar lo divino, el absoluto fundamento de las creencias, de aquello que existe en y por sí mismo, y, que implica un comportamiento de temor y de reverencia frente a lo divino a través de los ritos institucionales del Estado. Así pues, para Hegel el papel de la religión no solo consiste en representar el fundamento divino de una comunidad, sino también en legitimar las instituciones políticas modernas, que son las bases para el desarrollo de la agencia individual capaz de autolimitarse por respeto a lo absoluto encarnado en la comunidad. En este sentido, la religión cumple con ser una forma de representación y legitimación 
teórico-práctica del fundamento en el cual los sujetos pueden reconocerse como parte de una comunidad política de individuos.

Al final del punto sobre la moralidad y el perdón, Hegel muestra como una concepción de la comunidad moderna que reconcilia a sus miembros debe ser una comunidad religiosa de un cierto tipo, vale decir, una estructura de reconocimiento mutuo que permita a sus miembros alcanzar la reconciliación de cada uno con el otro y de todos con su carácter de individuos. Esta concepción solo puede ser el cristianismo, ya que en él cada sujeto se reconoce en el otro como Sujeto universal, capaz de autodeterminarse como un ser libre y, por eso, digno de respeto. En efecto, solo en la comunidad cristiana Dios está presente en el otro, generando una actitud de reverencia y autolimitación del propio ego en forma recíproca entre los sujetos.

De acuerdo con Hegel la reconciliación en la religión se da entre la naturaleza infinita y universal de la voluntad divina y la orientación particular de la voluntad humana a través de la presencia de Cristo en la tierra. Gracias a él la voluntad humana puede volverse un momento singular de la voluntad universal, es decir, determinarse, porque es modelo de voluntad cuyo deseo se orienta al amor infinito de Dios mediado por los otros hombres. Y es que la determinación de la voluntad solo se puede lograr a través del otro, en la interacción con el prójimo, pero, sobre todo, a través de reconocer la propia voluntad en la voluntad del otro, que se encarna como la voluntad de la comunidad cristiana en donde Dios se determina (Williams, 2017).

En la comunidad cristiana la construcción de la autoconciencia devino en un proyecto histórico por alcanzar el consenso sobre la identidad colectiva. En este proyecto la moralidad cristiana jugó un papel formativo que terminó por secularizar y convertir a la identidad comunitaria en una forma racional de identidad colectiva que será el resultado del desarrollo de la autoconciencia del Espíritu europeo.

\section{CONCLUSIONES:}

Para entender el papel que juega la religión en las relaciones de reconocimiento, nos posicionamos dentro de la historia del surgimiento del concepto de reconocimiento en el idealismo alemán y buscamos ubicar a la religión dentro del marco de la Fenomenología del Espíritu.

El reconocimiento surge en el idealismo alemán como una forma de reivindicar los ideales de igualdad de los sectores burgueses dentro de un contexto marcado por el orden feudal y señorial. Esto implicó una revolución del pensamiento que fue expresado por Immanuel Kant en su filosofía moral y su concepto clave fue el respeto. Para Kant el respeto es lo que manda la ley moral nacida de la razón práctica pero que solo puede ser motivada por otro, encarnación de la ley moral. Así pues, el respeto es una relación en la que el sujeto moral encuentra otro sujeto moral y por el cual limita su amor propio, vale decir, su egoísmo.

Hegel recoge esta noción de respeto, pero la transforma. A diferencia de Kant, para Hegel la autolimitación reciproca del egoísmo no es un deber sino una necesidad de reconocimiento por el otro que es mediada por la lucha y cumple un papel formativo de la identidad autónoma. Este proceso formativo se da mediado por las instituciones sociales en el proceso de socialización. A través 
del aprendizaje de convertirnos en agentes autónomos y eficaces de nuestra comunidad aprendemos a reconocer en el otro a un ser autónomo que merece respeto. Esto solo puede suceder si al relacionarnos con el otro mediante nuestros actos voluntarios reconocemos en este una extensión de nuestra propia estructura voluntaria, de forma tal que podamos experimentar las características y particularidades del otro como algo en lo que uno pueda identificarse. En términos de Hegel, solo se es libre siendo uno mismo en el otro.

En la Fenomenología del Espíritu Hegel desarrolla el camino de la experiencia de la conciencia desde la conciencia natural que se determina a sí misma en la inmediata oposición al otro, hasta el punto de vista de la Ciencia en donde es inteligible la absoluta y pura reconciliación entre el yo y el otro. Este camino es una estructura de categorías que tienen un sentido epistemológico y ontológico. En cada figura de la conciencia, esta no solo va ir afirmando la verdad sobre sí misma, sino también, lo que ella es en realidad. Por esto, cada figura de la conciencia es una forma de autoconciencia o autoidentidad que se desarrolla orgánicamente como un todo. Ninguna forma o figura es un error absoluto sino tan solo una parcialidad de la totalidad que hasta no llegar al punto de vista de la ciencia no será autoconsciente en forma plena.

Hasta la sección Razón de la Fenomenología se abordan las relaciones comunitarias en un sentido formal, abstraídas del contenido espiritual del contexto histórico y social concreto. Sin embargo, en la sección Espíritu Hegel entra a la descripción histórica de comunidades concretas y al papel formativo de la historia en el camino hacia la perspectiva de la ciencia. La historia, o, como la llama
Hegel, la historia actual, juega el papel de llevar las formas de la mera conciencia a formas de mundo y mostrar, así, como las comunidades reales, en el sentido estricto de la palabra, median las afirmaciones de la autoconsciencia.

La religión es la figura con la cual el Espíritu toma consciencia de sí a través de lo absoluto que determina esencialmente lo que es la vida humana. La autoconciencia religiosa lleva a los agentes individuales más allá de su estado de egoísmo natural hacia un estado comunitario o de comunidad en el cual estos aceptan razones, obligaciones y proscripciones que les imponen límites objetivos en sus creencias y acciones por estar revestido de lo divino o sagrado. En particular, en la moralidad cristiana el otro es un prójimo en el cual reconocemos la presencia de Dios, lo que implica una actitud de respeto y autolimitación del amor propio. En esta relación con el otro, el cristiano reconcilia su voluntad particular con la voluntad universal de Dios, porque ama lo que Dios ama y, de este modo, determina su voluntad en una orientación universal.

La relación de reconocimiento entre cristianos determina la presencia de Dios en sus prácticas institucionales, por lo que asistimos a la formación de una identidad comunitaria de naturaleza universal que permiten a sus miembros alcanzar su carácter de individuos, sujetos dignos de respeto mutuo. La construcción histórica de esta identidad deviene en proyecto por alcanzar el acuerdo colectivo sobre la determinación de quienes son, pero que tiene un claro desarrollo en la formación del Espíritu europeo.

En suma, la religión juega el papel de una forma reflexiva de la comunidad en donde el Espíritu encuentra su identidad 
en lo absoluto de la vida humana, vale decir, en la encarnación de Dios: Cristo. Hegel fundó esta forma de la autoconciencia en una estructura de reconocimiento mutuo entre individuos que reconocían mutuamente en el otro el valor de lo sagrado y lo divino que inspiran respeto mutuo. De esta manera, la religión cristiana cumple el rol político de representar a la consciencia la vida práctica de la sociedad moderna. Lo que no es azaroso, sino más bien, resultado del desarrollo sistemático de la autoconciencia en su camino hacia la perspectiva de la ciencia. Lo que al final, va a servir para argumentar la necesidad del desarrollo y realización de los ideales de la burguesía en lucha contra el orden social y señorial.

\section{REFERENCIAS BIBLIOGRÁFICAS}

Hegel, G. W. (2009). Fenomenología del Espíritu. Pre-Textos.

Honneth, A. (1992). La lucha por el reconocimiento Por una gramática moral de los conflictos sociales. Crítica.

Honneth, A. (2001). Leiden an Unbestimmheit Eine Reaktualisierung der Hegeleschen Rechtsphilosophie. Reclam.

Honneth, A. (2008). From desire to recognition: Hegel's account of human sociality . En D. Moyar, E a. M. Quante, Hegel's Phenomenology of Spirit A Critical Guide (págs. 76-90). Cambridge University Press.

Honneth, A. (2018). Anerkennung Eine europäische Ideengeschichte. Frankfurt: Suhrkamp.Kant, I. (1989). La Metafísica de las Costumbres. Editorial Tecnos.
Pinkard, T. (1994). Hegel's Phenomenology The Sociality of Reason. CambridgeUniversity Press.

Pinkard, T. (2002). German Philosophy 1760 - 1860 The Legacy of Idealism. Cambridge.

Pippin, R. (2008). Hegel's Practical Philosophy Rational Agency as Ethical Life . Cambridge University Press.

Siep, L. (2000). Hegel's Phenomenology of Spirit. Cambridge.

Siep, L. (2011). La lucha por el reconocimiento. La relación entre Hegel y Hobbes en los escritos de Jena. Estudios de Filosofía $N^{\circ} 43$ EneroJunio, 31-84

Stewart, J. (2010). Idealism and Existentialism Hegel and Nineteenth and Twentieth-Century European Philosophy. Continuum International Publishing.

Williams, R. (1997). Hegel's Ethic of Recognition. University of California Press.

Williams, R. (2017). Hegel on the Proofs and the Personhood of God Studies in Hegel's Logic and Philosophy of Religion. Oxford University Press.

Fecha de recepción: 26/09/2021 Fecha de aceptación: 15/10/2021 
